DOI: https://doi.org/10.24164/prosiding.v3i1.17

\title{
TRANSPORTASI DI TATAR SUNDA
}

\section{Transportation in Tatar Sunda}

\author{
Iwan Hermawan
}

Balai Arkeologi Jawa Barat

Jalan Raya Cinunuk KM.17 Cileunyi Jawa Barat

E-mail: iwan1772@gmail.com

\begin{abstract}
Transportation is one of the human efforts in living on the face of the earth and this activity has been going on for generations, including in Sundanese people. The growing transport process of the community will be affected by the goods that must be transported and the time and mileage. This condition encourages the development of transport technology. Individual transport (carried, upheld, or carried) develops by utilizing carts when the number of goods must be transported is more. The development of transportation technology is growing as engine powers to begin to be applied for transportation facilities. This condition encourages increased volume of goods and passengers transported, and travel times are getting faster and longer mileage. The development of transportation technology, not in total replaces the role of traditional transportation technology in the community but complements each other .
\end{abstract}

Keywords: transportation, transportation technology, Sundanese people.

\section{Abstrak}

Pengangkutan merupakan salah satu bentuk upaya manusia dalam menjalani kehiduan di muka bumi dan kegiatan ini telah berlangsung secara turun temurun, termasuk pada masyarakt Sunda. Proses pengangkutan yang berkembang di masyarakat akan dipengaruhi oleh barang yang harus diangkut dan waktu serta jarak tempuh. Kondisi ini mendorong perkembangan teknologi pengangkutan. Pengangkutan secara individual (dijinjing, dijunjung, atau dipikul) berkembang dengan memanfaatkan gerobak ketika jumlah barang yang harus diangkut lebih banyak. Perkembangan teknologi pengangkutan semakin berkembang ketika tenaga mesin mulai diaplikasikan di sarana angkutan. Kondisi ini mendorong meningkatnya volume barang dan penumpang yang diangkut, serta waktu tempuh semakin cepat dan jarak tempuh semakin jauh. Perkembangan teknologi pengangkutan tersebut, tidak secara total menggantikan peran teknologi angkutan tradisional di tengah masyarakat namun saling melengkapi.

Kata kunci: pengangkutan, teknologi pengangkutan, masyarakat Sunda.

\section{PENDAHULUAN}

$\mathrm{K}$ omunikasi dan trasnportasi merupakan dua hal penting dalam upaya memenui kebutuhan hidup masyarakat. Perkembangan sarana transportasi terus terjadi seiring dengan berkembangnya teknologi dan masyarakat. Pada awalnya, untuk mobilitas antar daerah dan wilayah, masyarakat hanya mengandalkan kaki untuk berjalan dan tangan untuk membawa barang. Lambat laun, moda transportasi dan alat angkut berkembang untuk memudahkan manusia bermigrasi dan mengangkut. Pada awalnya hubungan antar wilayah di suatu pulau atau daratan dilakukan manusia dengan berjalan kaki atau menunggang hewan (Kuda, Gajah) atau menaiki kendaraan (gerobak) yang dihela oleh binatang. Kuda, Sapi, dan 
Kerbau merupakan binatang yang dipilih oleh kebanyakan manusia sebagai alat transportasi, namun di beberapa daerah, seperti di Ciamis Jawa Barat dan di Kotabumi Lampung dikenal adanya gerobak yang ditarik oleh kambing atau domba. Gerobak yang ditarik oleh kambing atau domba tersebut bukan untuk angkutan penumpang, namun angkutan hasil pertanian atau barang lainnya.

Tata Sunda merupakan daerah yang memiliki morfologi beragam, dari mulai pesisir, dataran rendah yang luas di bagian utara, deretan pegunungan muda di bagian tengah, dataran pesisir serta dataran rendah yang sempit dengan tebing-tebingnya yang terjal di bagian selatan. Kondisi lingkungan alam tersebut membentuk masyarakatnya melakukan adaptasi lingkungan dalam memenuhi kebutuhan mereka sebagai mahluk sosial. Pertama mereka melakukan penjelajahan ke wilayah pedalaman dengan menggunakan perahu, menyusuri sungai dari muara, dilanjutkan dengan berjalan kaki menembus belantara atau menggunakan kuda sebagai alat angkut. Perkembangan berikutnya, dibuat jalan setapak yang dapat dilalui oleh kuda, dan kemudian ditingkatkan menjadi dapat dilalui oleh gerobak yang ditarik oleh hewan, seperti kuda, sapi atau kerbau. Seiring dengan berkembangnya teknologi transportasi darat, jalan raya tersebut terus ditingkatkan kualitasnya hingga dapat dilalui oleh semua jenis kendaraan.

Ketika teknologi semakin berkembang, transportasi pun demikian. Berkembangnya teknologi mesin uap mendorong pembangunan perkeretaapian di Nusantara, termasuk di Tatar Sunda. Jalan-jalan rel dibangun dati Batavia ke Buitenzorg (Bogor) terus ke Sukabumi, Bandung, Tasikmalaya,
Banjar, sampai Cilacap dan bersambung dengan jalur kereta api yang menghubungkan Yogyakarta dengan Cilacap. Berkembangnya teknologi mesin kendaraan juga mendorong berkembangnya teknologi angkutan jalan raya, yaitu dengan berkembangnya mobil sebagai moda angkutan.

Pada masa kerajaan Sunda yang berpusat di Pakuan yang berada jauh dari pantai, transportasi yang menghubungkan antara Laut Jawa dengan Pakuan, adalah transportasi Sungai. Ci Liwung merupakan jalur utama bagi lalu lintas antara Pakuan dengan Pelabuhan Kalapa yang berada di pesisir utara Pulau Jawa. Tome Pires memberitakan bahwa Perjalanan dari kota pelabuhan Kalapa ke Ibukota Pakuan memerlukan waktu dua hari pelayaran melalui Ci Liwung, dan sungai di Pelabuhan Cirebon dapat dilayari sampai jauh ke daratan. Pengangkutan melalui sungai terus berlanjut sekurangnya sampai pertengahan abad ke-19. Penguasa Belanda membangun gudang-gudang penyimpanan hasil perkebunan di Cikao, Purwakarta yang merupakan pelabuhan sungai $\mathrm{Ci}$ Tarum, dan di Karangsambung yang merupakan pelabuhan sungai $\mathrm{Ci}$ Manuk. Gudanggudang tersebut diperuntukan untuk penyimpanan/penampungan sementara hasil perkebunan dan pertanian dari pedalaman serta sebagai penyimpanan barang-barang yang diperlukan masyarakat di pedalaman sebelum didistribusikan (Ekadjati, 2005, hal. 101, 164, 165).

Berdasarkan uraian tersebut, permasalahan yang dibahas pada tulisan ini adalah Bagaimana perkembangan sarana transportasi di Tatar Sunda. Tujuannya adalah untuk mendeskripsikan perkembangan transportasi di tatar sunda Tatar Sunda memiliki kondisi alam dan 
lingkungan dengan topografi yang beragam, yaitu pesisir dan dataran rendah yang luas di utara, pegunungan lipatan muda di tengah tengan topografi yang ekstrem, dan dataran pantai yang sempit di Selatan.

Guna menjawab permasalahan yang diajukan, metode yang dipergunakan pada penulisan tulisan ini adalah metode deskriptif analisis. Data yang dipergunakan merupakan data pustaka dan data dari hasil penelitian arkeologi tentang perkeretaapian yang dilakukan Balai Arkeologi Jawa Barat tahun 2014-2019.

\section{PEMBAHASAN}

\section{Pembangunan Jalan Daendels}

Sampai pertengahan abad ke-18, perjalanan dari Batavia ke pedalaman Priangan dilakukan dengan naik perahu atau rakit melewati $\mathrm{Ci}$ Tarum dan $\mathrm{Ci}$ Manuk. Baru pada tahun 1786, jalan setapak yang dapat dilewati kuda mulai menghubungkan Batavia, Buitenzorg, Cianjur, dan Bandung. Ketika Daendels datang ke Hindia Belanda tahun 1808, dirinya turun di Anyer dan melakukan perjalanan darat menuju Batavia, waktu tempuh perjalanan mencapai 4 hari. Pada kesempatan lain, dia juga melakukan perjalanan dari Buitenzorg ke Semarang melalui Bandung guna melakukan konsolidasi dengan pembesar pribumi. Perjalanan tersebut dilakukannya dengan menggunakan kereta kuda dan memakan waktu tempuh 10 hari. Perjalanan melalui darat tersebut dilakukan karena pada masa tersebut Laut Jawa sudah diblokir oleh Pasukan Angkatan Laut Inggris (Hermawan, 2010).

Perjalanan antar kota berhari-hari melalui jalur darat yang memakan waktu berhari-hari tersebut oleh Daendels dianggap terlalu lama dan menghambat distribusi pangan serta menghambat mobilitas pasukan tentara dan logistik ketika diperlukan. Untuk mengatasinya maka diperlukan sarana transportasi darat yang memadai yang menghubungkan pantai barat dengan pantai timur Pulau Jawa. Tujuannya agar waktu tempuh perjalanan darat antar kota di sepanjang Pulau Jawa dapat dipersingkat. Mengingat usulan pembangunan jalan baru dipastikan tidak akan dikabulkan oleh pemerintah Kerajaan Belanda dengan alasan akan memakan biaya besar dan menguras kas pemerintah, maka Daendels mengajukan usulan perbaikan sistem jalan di Pulau Jawa, bukan usulan pembangunan jalan baru.

Pada pelaksanaannya, Daendels memperaiki jalan dari Cisarua sampai Karangsambung sepanjang $150 \mathrm{~km}$. Untuk memperbaiki jalan raya sisanya, pada tanggal 5 Mei 1808 Daendels memerintahkan aparat pemerintahan di sepanjang Pulau Jawa untuk mengerahkan pekerja Rodi (tidak dibayar) yang tugasnya memperbaiki dan meningkatkan kualitas jaringan jalan yang sudah ada hingga dapat dilalui semua jenis kendaraan. Ruas jalan raya tersebut merupakan bagian dari jalan desa yang dirintis dan ditempuh oleh Pasukan Sultan Agung ketika menyerang Batavia tahun 1628 dan 1630. Setelah satu tahun pengerjaan (1808-1809), jalan raya yang membentang dari Pantai Barat sampai Pantai Timur Pulau Jawa sepanjang $1000 \mathrm{~km}$ terwujud (Kunto, 1984, 1986).

Pembangunan jalan raya pos yang membentang sepanjang $1000 \mathrm{~km}$ dari Anyer sampai Panarukan merupakan bentuk revolusi pembangunan sarana transportasi di Pulau Jawa. Bagi kawasan Priangan yang berada di pedalaman Jawa Barat, keberadaan jalan raya pos menjadi pembuka dari ketertutupan Priangan dari kawasan pantai. 
Pegunungan yang tinggi dengan lembah yang dalam seolah menjadi benteng yang sulit ditembus. Hal ini pula yang menjadikan jalur Priangan sebagai jalur pelarian saat Inggris menyerang Batavia. Gubernur Jenderal Jansen, yang menggantikan Gubernur jenderal HW. Daendels, berhasil kerluar dari benteng pertahanan Mesteer Cornelis dan berkuda menuju Istana Bogor selanjutnya melalui jalan raya pos ke Priangan, Sumedang, Cirebon, Semarang, dan melakukan perlawanan di Ungaran sampai akhirnya berhasil ditangkap oleh Pasukan Inggris (Thorn, 2011, hal. 41-98).

Keberadaan Jalan raya Pos berhasil meningkatkan komunikasi dan transportasi antar kota dan antar wilayah di Pulau Jawa. Pergeseran moda transportasi yang digunakan terjadi, dari awalnya lebih dominan penggunaan sarana angkutan laut dan sungai bergeser menjadi penggunaan transportasi darat. Keberadaan jalan raya pos juga mendorong peningkatan eksploitasi pedalaman Jawa, terutama di Jawa Barat. Daerah Pedalaman Jawa Barat yang subur atau Tataran Sunda dan dilewati oleh Jalan Raya Pos mendorong pembukaan perkebunan-perkebunan komoditas yang laku di pasaran dunia, seperti Kopi, dan Teh.

\section{Angkutan Komoditas Perkebunan}

Kopi merupakan salah satu komoditas perdagangan yang laku di pasaran dunia. Tanaman Kopi menjadi tanaman wajib yang ditanam di Priangan sejak tahun 1707. Penanamannya dilakukan oleh pekerja-wajib yang pengorganisasiannya diserahkan kepada Bupati dan dilakukan dengan sistem feodal. Melalui sistem kerja paksa, penduduk diwajibkan mengerjakan pembukaan hutan, penggarapan lahan, penanaman biji kopi, pemeliharaan, dan pemanenan, serta pengangkutan dari kebun ke tempat pengepulan yang telah ditetapkan. Dari penyerahan penduduk, Bupati meneruskannya untuk diserahkan kepada VOC, sebagai produksi penyerahan wajib (Kartodirdjo \& Suryo, 1991).

Pengangkutan Kopi dari kebun ke pusat pengepulan dilakukan penduduk dengan cara dipikul. Hal ini dilakukan, karena kondisi kebun kopi berada di daerah yang sulit dijangkau oleh gerobak. Tanaman kopi banyak ditanam di lereng-lereng terjal perbukitan Tatar Sunda. Setelah terkumpul, dari tempat pengepulan pengangkutan Kopi ke gudang-gudang yang berada di Kabupaten dilakukan dengan gerobak-gerobak yang ditarik oleh Kerbau. Setelah diserahkan kepada VOC oleh bupati, kopi-kopi tersebut selanjutnya diangkut ke pelabuhan dengan menggunakan gerobak dan atau perahuperahu yang menyusuri sungai $\mathrm{Ci}$ Liwung, Ci Tarum atau Ci Manuk.

\section{Pembangunan Jalur Kereta Api}

Perang Diponegoro (1825-1830) telah menguras kas pemerintah kolonial Belanda, sehingga diperlukan berbagai terobosam agar kas tersebut terisi kembali. Kebijakan untuk mengisi kas pemerintah yang kosong dilakukan melalui kebijakan tanam paksa (culture stelsel). Kebijakan yang dikeluarkan oleh Gubernur Jenderal Johannes van den Bosch ini mengharuskan setiap pemilik lahan untuk menanami 1/5 lahannya dengan tanaman wajib yang laku di pasaran dunia. Kewajiban tersebut termasuk pemeliharaan tanaman serta pemetikan dan penyerahan hasilnya kepada pemerintah. Rakyat juga dibebani pajak lahan dalam bentuk barang (in-natura) berupa hasil pertanian. Jika kewajiban membayar pajak lahan tidak terpenuhi, diganti dengan menyediakan 
waktu bekerja selama 66 hari dalam satu tahun (Tim Telaga Bakti Nusantara, 1997, hal. 13).

Sejak diberlakukannya tanam paksa dan berlanjut dengan liberalisasi, hasil perkebunan yang merupakan produk unggulan ekspor terus meningkat dan mendorong dikembangkannya transportasi massal pengangkut hasil perkebunan. Hasil perkebunan yang meningkat dengan pesat pada akhirnya banyak menumpuk di gudang-gudang yang jauh dari pelabuhan atau terlambat sampai di pelabuhan akibat minimnya sarana pengangkut. Kondisi tersebut diperparah dengan banyaknya hewan penarik, terutama Sapi yang mati pada tahun 1840, akibat hewan-hewan tersebut dipaksa untuk menempuh jarak yang jauh dengan beban yang berlebih. Pada sisi lain, pembiayakannya hanya berlangsung secara alamiah. Keadaan ini mendorong meningkatnya harga sapi di pasaran dan mendorong kenaikan biaya angkut komoditi dari pusat-pusat perkebunan ke pelabuhan. Penyelesaian masalah yang dilakukan oleh menteri urusan penjajahan JC Baud dengan cara mendatangkan 40 ekor Unta dan sejumlah keledai ke pulau Jawa gagal, karena semua binatang tersebut mati (Tim Telaga Bakti Nusantara, 1997, hal. 1618). Akibat yang ditimbulkan oleh krisis angkutan tersebut, adalah menumpuknya hasil perkebunan dan Industri di gudanggudang perusahaan yang berpengaruh pada penurunan kualitas barang; serta terlambatnya barang-barang kebutuhan warga yang didatangkan dari luar. Kondisi tersebut mendorong untuk pengembangan moda angkutan massal yang mampu mengangkut barang dalam jumlah banyak dengan waktu tempuh yang lebih cepat. Pilihan jatuh pada pengembangan angkutan rel atau kereta api. Hal ini didasarkan pada keberhasilan pengembangan kereta api di Eropa.

Pembangunan jalur kereta api pertama adalah jalur Semarang - Vorstenlanden (Tanah Kerajaan, sebutan untuk Yogyakarta) yang dibangun oleh Perusahaan Kereta Api Swasta NISM (Nederlandsch Indische Spoorweg Maatschappij) dengan lintas cabang ke Ambarawa. NISM memulai pembangunannya di Desa Kemijen, Semarang pada tanggal 7 Juni 1864. Pada tanggal 10 Agustus 1867, secara resmi jalur Semarang - Tanggung mulai dibuka

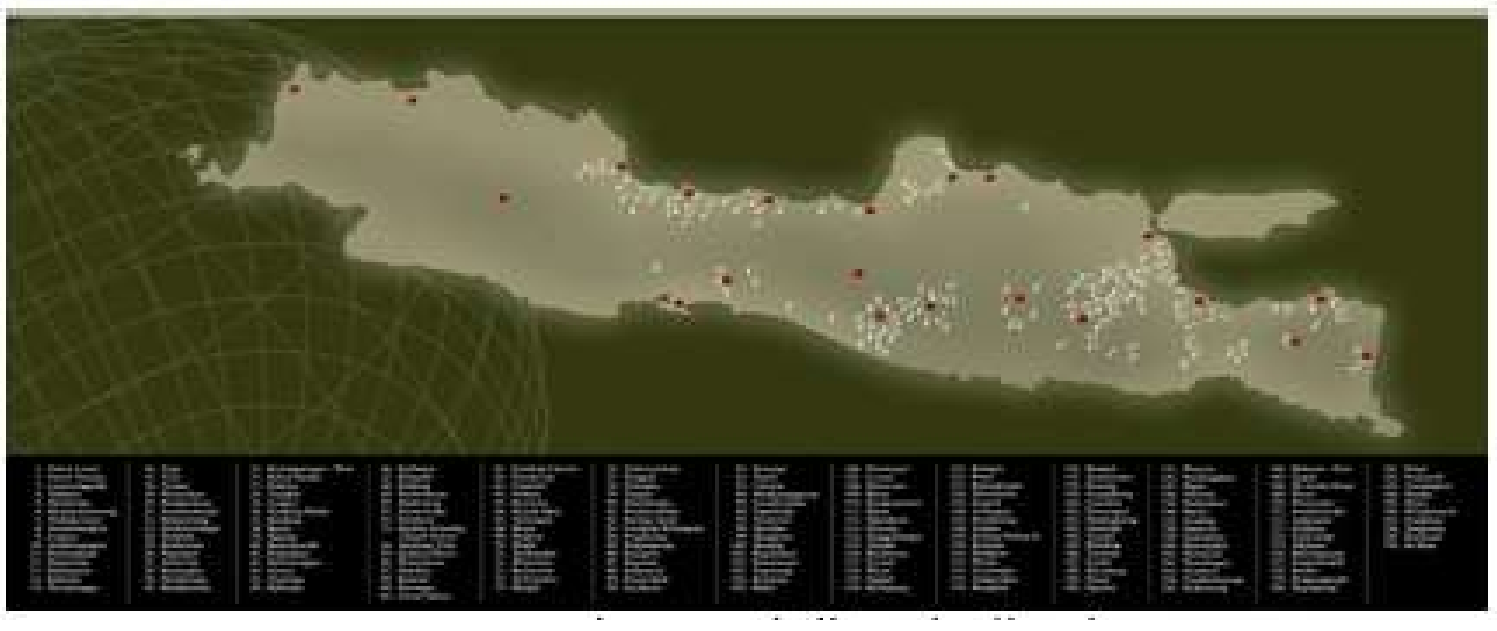

Gambar 1. Persebaran Pabrik Gula di Pulau Jawa (Sumber: Krisprantono, 2014). 
untuk melayani angkutan umum dan secara keseluruhan Jalur Semarang - Yogyakarta dengan lintas cabang ke Ambarawa dibuka pada tanggal 21 Mei 1873. Di Wilayah Jawa Bangian Barat, pembangunan jalur kereta api mulai dikembangkan ketika NISM memperoleh konsesi Jalur Batavia (Jakarta) - Buitenzorg (Bogor) berdasarkan SK Gubernur jenderal Hindia Belanda No. 1 tanggal 27 Maret 1864 dan nomor 1 tanggal 19 Juni 1865, serta Keputusan Raja Belanda (Koninklijk Besluit) tanggal 22 Juli 1668. Pembangunan jalur Batavia - Buitenzorg baru dimulai tahun 15 Oktober 1869 dan resmi dibuka untuk umum pada bulan September 1871 untuk sebagian jalur dan pada tanggal 31 Januari 1873 jalur Batavia - Buitenzorg secara resmi tersambung (Tim Telaga Bakti Nusantara, 1997: 54-59).

Pembangunan perkeretaapin di Wilayah Jawa Barat terus berlangsung, baik dilakukan oleh Perusahaan Kereta Api milik pemerintah maupun Perusahaan Kereta Api Swasta, hingga tahun 1930-an. Perusahaan Kereta Api milik Permerintah, Staatsspoorwegen (SS) membangun jalur kereta api jarak jauh dari Buitenzorg ke Cilacap melalui Bandung dan beroperasi secara keseluruhan pada 1 November 1894. Perjalanan kereta api jalur Buitenzor - Bandung resmi beroperasi tanggal 17 Mei 1884. Batavia - Cilacap via Bandung akhirnya tersambung langsung setelah jalur Batavia - Buitenzorg milik NIS diambil alih oleh SS pada tahun 1913. Ke arah Barat, SS membangun jalur kereta api Batavia - Anyerkidul dengan lintas cabang ke Labuan yang resmi beroperasi tahun 1900 dan lintas cabang Cilegon - Merak pada tahun 1904. Ke Timur, SS mengambil alih jalur Batavia - Kedunggede dari BOS pada tahun 1898, membangun jalur Karawang Padalarang yang mulai beroperasi tanggal 2 Mei 1906, membangun jalur Cikampek
- Cirebon yang resmi digunakan tanggal 3 Juni 1912, dan membangun jalur Cirebon - Kroya yang resmi tersambung tanggal 1 Januari 1917. Selain itu SS juga membangun lintas cabang ke kota-kota kecil dari lintas utama yang dibangunnya.

Perusahaan kereta api lainnya yang membangun jalur kereta api di Jawa Barat, adalah SCS (Samarang Chirebon Stoomtram Masschappij) yang membangun dan mengoperasikan jalur Semarang - Cirebon yang secara keseluruhan tersambung tahun 1901. Jalur ini dikenal dengan sebutan jalur Gula karena SCS membangun jalur ini utamanya untuk memfasilitasi keberadaan Pabrik Gula yang banyak dibangun di antara Semarang - Cirebon, sehingga jalurnya masuk dibangun dekat atau memasuki kawasan pabrik gula.

Berdasarkan uraian tersebut, lompatan pembangunan sarana transportasi daratterjadi dengan dibangunnya sarana perkeretaapian. Waktu tempuh yang lebih singkat dan daya angkut yang lebih besar menjadikan kereta api banyak dipilih para pengusaha industri dan perkebunan sebagai sarana pengangkut hasil industri dan perkebunan, termasuk hasil pertanian dan hasil hutan.

\section{Transportasi Udara}

Sarana angkutan lainnya yang dikembangkan di Tatar Sunda, adalah transportasi udara yang mulai berkembang di dekade ke-2 Abad ke-20. Pembangunan transportasi udara di Tatar Sunda pada awalnya ditujukan untuk kepentingan militer. Pembangunan lapangan terbang di Bandung dilakukan tahun 1917 dan 1920, yaitu lapang terbang Rancaekek dan Arcamanik setelah sebelumnya membangun lapang terbang Kalijati, Subang. Akibat selalu tergenang air dan becek di musim penghujan, kedua lapang 
terbang tersebut ditinggalkan dan dibangun lapangan terbang baru di Andir, Cibeureum. Lapangan terbang ini resmi beroperasi pada tahun 1921 serta difungsikan sebagai lapangan terbang dan tempat pemeliharaan pesawat (bengkel) (Kunto, 1984; Sumbodo, 2017).

Keberadaan lapangan terbang Andir juga mendukung kemajuan penerbangan sipil dan pariwisata Bandung. Pesawat terbang Fokker VIIb Trimotor milik maskapai penerbangan belanda KLM (Koninklijke Luchtvaart Maatschappij) yang melayani penerbangan Batavia - Amsterdam selalu mampir di Bandung untuk melakukan perawatan pesawat sekaligus membawa penumpang, surat dan paket pos. Demikian pula dengan maskapai penerbangan KNILM (Koninklijke Nederlandsch-Indische Luchtvaart Maatschappij) membuka layanan rute Batavia-Bandung sehari sekali yang dilakukan sejak November 1928 (Sumbodo, 2017).

\section{Angkutan Komoditas}

Kopi merupakan salah satu komoditas perdagangan yang laku di pasaran dunia. Tanaman Kopi menjadi tanaman wajib yang ditanam di Priangan sejak tahun 1707. Penanamannya dilakukan oleh pekerja-wajib yang pengorganisasiannya diserahkan kepada Bupati dan dilakukan dengan sistem feodal. Melalui sistem kerja paksa, penduduk diwajibkan mengerjakan pembukaan hutan, penggarapan lahan, penanaman biji kopi, pemeliharaan, dan pemanenan, serta pengangkutan dari kebun ke tempat pengepulan yang telah ditetapkan. Dari penyerahan penduduk, Bupati meneruskannya untuk diserahkan kepada VOC, sebagai produksi penyerahan wajib (Kartodirdjo \& Suryo, 1991).
Pengangkutan Kopi dari kebun ke pusat pengepulan dilakukan penduduk dengan cara dipikul. Hal ini dilakukan, karena kondisi kebun kopi berada di daerah yang sulit dijangkau oleh gerobak. Tanaman kopi banyak ditanam di lereng-lereng terjal perbukitan Tatar Sunda. Setelah terkumpul, dari tempat pengepulan pengangkutan Kopi ke gudang-gudang yang berada di Kabupaten dilakukan dengan gerobak-gerobak yang ditarik oleh Kerbau. Setelah diserahkan kepada VOC oleh bupati, kopi-kopi tersebut selanjutnya diangkut ke pelabuhan dengan menggunakan gerobak dan atau perahuperahu yang menyusuri sungai $\mathrm{Ci}$ Liwung, Ci Tarum atau Ci Manuk.

Setelah beroperasinya kereta api di wilayah Tatar Sunda, maka pengangkutan komoditas yang dihasilkan Perusahaanperusahaan Perkebunan di wilayah Tatar Sunda ke gudang-gudang pelabuhan di Tanjungpriok dilakukan dengan menggunakan kereta api. Di setiap stasiun, termasuk stasiun kelas halte, selalu tersedia gudang-gudang komoditas sebagai penampung sementara komoditas yang akan diangkut ke pelabuhan.

\section{Angkutan Tambang}

Teknologi pengangkutan yang berkembang di Jawa Barat, adalah teknologi pengangkutan hasil tambang. Tambang Emas Cikotok di Banten Selatan merupakan tambang yang menggunakan teknologi mutakhir pada masanya dalam sistem pengangkutan hasil tambang dari titik penggalian ke pabrik pengolahan. Pembangunan tambang Emas Cikotok dilakukan oleh Perusahaan Swasta Belanda, NV. Mijnbouw Maarschappy Zuid Bantam (NV. MMZB) selama tiga tahun, yaitu 1936 - 1939. Pembukaan tambang dilakukan di 

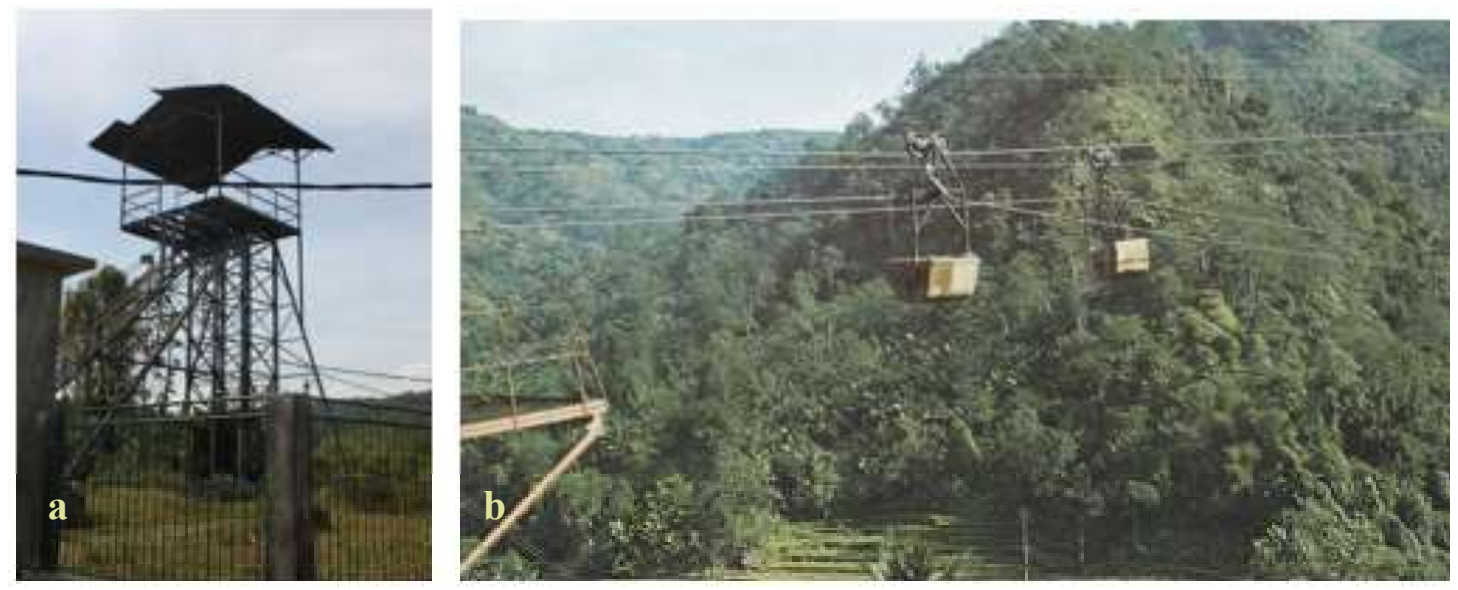

Gambar 2. (a) Derek Vertikal (lori vertikal) (Dok. Balar Bandung, 2013); (b) Lori Gantung (Kabelbaan) (Dok. PT. ANTAM, Pascatambang Cikotok, 2012).

Cikotok dan Cipicung, pembangunan Pabrik Pengolahan Bijih Emas di Pasirgombong, serta dibangun jaringan lori gantung (kabelbaan) sebagai sarana pengangkutan bijih. Pada tahun 1939, Pabrik Pasirgombong mulai berproduksi dengan mengolah bijih dari tambang Cikotok dan Cipicung. Produksi tersebut berlangsung sampai pecahnya Perang Dunia II dan masuknya Jepang ke Indonesia pada tahun 1942 (Hermawan, 2014).

Sistem penambangan yang dilakukan di Tambang Emas Cikotok sebagian besar tambang tertutup berupa lubang tambang vertikal dan lubang tambang horizontal. Pada tambang vertikal di Pasirlaban, Cikotok, lubang tambang utama berupa lubang vertikal dengan kedalaman mencapai 110 meter. Lubang utama ini menghubungkan permukaan dengan lubang tambang horizontal pada kedalaman tertentu, sehingga membentuk tingkatan/level lubang tambang yang digali mengikuti jalur bijih emas.

Pengangkutan hasil tambang dan pekerja tambang di lubang tambang vertikal Cikotok dilakukan dengan menggunakan lift atau derek vertikal. Selanjutnya, bijih disalurkan ke penampungan sementara untuk selanjutnya dikirim ke pabrik pengolahan.

Pada lubang tambang Horizontal, seperti di lubang Cirotan, lubang tambang utama dibangun secara horizontal (terowongan) hingga mencapai batuan bijih. Panjang terowongan bisa mencapai $1 \mathrm{~km}$ bahkan lebih. Pada lubang horizontal, pengangkutan bijih emas ke luar lubang dilakukan dengan menggunakan lori yang ditarik dengan lokomotif Diesel. Selanjutnya, bijih dikirim ke pabrik pengolahan.

Pengangkutan bijih dari penampungan sementara di lokasi tambang ke pabrik pengolahan dilakukan dengan menggunakan lori gantung (Kabelbaan). Lori gantung tersebut membentang sepanjang $5 \mathrm{~km}$ dari Pabrik Pengolahan di Pasirgombong ke tambang vertikal Pasirlaban, dan $15 \mathrm{~km}$ ke tambang Cirotan

\section{SIMPULAN}

Perkembangan Transportasi di Tatar Sunda dipengaruhi oleh kondisi lingkungan geografis Tatar Sunda yang merupakan dataran redah yang luas di pesisir utara, Pegunungan lipatan muda dengan topografi 
yang ekstrem di bagaian tengah, dan dataran rendah yang sempit di pesisir selatan. Kondisi tanahnya yang subur mendorong berkembangnya perkebunan dan pertanian. Hasil yang melimpah tidak sebanding dengan ketersediaan angkutan yang berakibat pada banyaknya hasil pertanian dan perkebunan yang rusak akibat tidak bisa diangkut ke pelabuhan. Perkembangan teknologi pengangkutan yang berkembang secara pesat medorong untuk dikembangkannya moda angkutan penumpang dan komoditas di tatar sunda guna memenuhi kebutuhan Industri dan pergerakan manusia.

Pengembangan berbagai moda transportasi di Tatar Sunda berjalan seiring sejalan antar moda angkutan. Keberadaannya saling mendukung antara satu satu moda angkutan dengan moda angkutan lainnya.

\section{DAFTAR PUSTAKA}

Ekadjati, E. S. (2005). Kebudayaan Sunda (2): Zaman Pajajaran. Jakarta: Pustaka Jaya.

Hermawan, I. (2010). Nilai Strategis Jalan Daendels Bagi Pertahanan Hindia Belanda di Pulau Jawa: Kajian Geografi Sejarah. In W. R. Wahyudi (Ed.), Dari Masa Lalu ke Masa Kini : Kajian Budaya Materi, Tradisi, dan Pariwisata (hal. 107-118). Bandung: Alqaprint.
Hermawan, I. (2014). Lori Gantung: Transportasi Hasil Tambang di Pertambangan Emas Cikotok. PURBAWIDYA: Jurnal Penelitian dan Pengembangan Arkeologi, 3(1), 15-26. https://doi.org/10.24164/ PW.V3I1.2

Kartodirdjo, S., \& Suryo, D. (1991). Sejarah Perkebunan di Indonesia: Kajian Sosial Ekonomi. Yogyakarta: Aditya Media.

Kunto, H. (1984). Wajah Bandoeng Tempo Doeloe. Bandung: Granesia.

Kunto, H. (1986). Semerbak Bunga di Bandung Raya. Bandung: Granesia.

Sumbodo, S. (2017). Andir, De Fabriek dan Lapangan Terbang LA - Aviation History of Indonesia. Diambil 8 Oktober 2020, dari https:// aviahistoria.com/2017/08/03/andirde-fabriek-dan-lapangan-terbang-la/

Thorn, W. (2011). Penaklukan Pulau Jawa: Pulau Jawa di Abad Sembilan belas dari Amatan Seorang Serdadu Kerajaan Inggris (Novriatri, Penerj.). Elex Media Komputindo.

Tim Telaga Bakti Nusantara. (1997). Sejarah Perkeretaapian Indonesia Jilid 1. Bandung: Angkasa.

\section{HASIL DISKUSI}

\section{> Tidak ada pertanyaan}

